\title{
Community-wide outbreak of haemolytic uraemic syndrome associated with Shiga toxin 2-producing Escherichia coli O26:H11 in southern Italy, summer 2013
}

C Germinario ${ }^{1}$, A Caprioli 2 , M Giordano ${ }^{3}$, M Chironna ${ }^{1}$, MS Gallone ${ }^{1}$, S Tafuri ${ }^{1}$, F Minelli 2 , A Maugliani ${ }^{2}$, V Michelacci ${ }^{2}$, L Santangelo ${ }^{3}, 0$ Mongelli ${ }^{4}, \mathrm{C}_{\text {Montagna }}{ }^{5}, \mathrm{G}$ Scavia ${ }^{2}$, on behalf of all participants of the Outbreak investigation team ${ }^{6}$

1. Department of Biomedical Science and Human Oncology, Aldo Moro University of Bari, Bari, Italy

2. Department of Veterinary Public Health and Food Safety, Istituto Superiore di Sanità, Rome, Italy

3. Paediatric Nephrology and Dialysis Unit, Children's Hospital Giovanni XXIII, Bari, Italy

4. Veterinary Public Health Office, Regione Puglia, Bari, Italy

5. Istituto Zooprofilattico Sperimentale della Puglia e Basilicata, Putignano, Italy

6. The members of the Outbreak investigation team are listed at the end of the article

Correspondence: Gaia Sofia Scavia (gaia.scavia@iss.it)

Germinario C, Caprioli A, Giordano M, Chironna M, Gallone MS, Tafuri S, Minelli F, Maugliani A, Michelacci V, Santangelo L, Mongelli O, Montagna C, Scavia G, on behalf of all participants of the Outbreak investigation team. Community-wide outbreak of haemolytic uraemic syndrome associated with Shiga toxin 2-producing Escherichia coli $026: \mathrm{H}_{11}$ in southern Italy, summer 2013. Euro Surveill. 2016;21(38):pii=30343. DOI: http://dx.doi.org/10.2807/1560-7917.ES.2016.21.38.303432

In summer 2013, an excess of paediatric cases of haemolytic uraemic syndrome (HUS) in a southern region of Italy prompted the investigation of a community-wide outbreak of Shiga toxin 2-producing Escherichia coli (STEC) 026:H11 infections. Case finding was based on testing patients with HUS or bloody diarrhoea for STEC infection by microbiological and serological methods. A case-control study was conducted to identify the source of the outbreak. STEC 026 infection was identified in 20 children (median age 17 months) with HUS, two of whom reported severe neurological sequelae. No cases in adults were detected. Molecular typing showed that two distinct STEC 026:H11 strains were involved. The case-control study showed an association between STEC 026 infection and consumption of dairy products from two local plants, but not with specific ready-to-eat products. E.coli 026: $\mathrm{H}_{11}$ strains lacking the stx genes were isolated from bulk milk and curd samples, but their PFGE profiles did not match those of the outbreak isolates. This outbreak supports the view that infections with Stx2-producing $E$. coli 026 in children have a high probability of progressing to HUS and represent an emerging public health problem in Europe.

\section{Introduction}

Haemolytic uraemic syndrome (HUS) is a rare disorder characterised by microangiopathic haemolysis, platelet consumption, and multi-organ damage (mainly to the kidneys) [1]. In its typical form, it occurs after a prodromal diarrhoea, usually due to Shiga toxin (Stx)producing Escherichia coli (STEC) infection. HUS is the most common cause of acute renal failure in childhood and occurs in ca $15 \%$ of children with STEC 0157 infections [1]. Although STEC 0157 is the predominant cause of paediatric HUS worldwide [1], cases associated with infections with STEC belonging to non-0157 serogroups have been increasingly reported [2-5].

In Italy, surveillance of HUS in children ( 15 years) was established in 1988 through the National Registry of HUS, carried out by the Italian Society for Paediatric Nephrology in cooperation with the National Reference Laboratory for E. coli [4]. Between 1988 and 2012, an average of 33 sporadic cases of HUS per year were observed in Italy, with a mean annual incidence of 0.4 cases per 100,000 residents aged $0-15$ years. The STEC serogroups most frequently reported were 0157 (35\%), O 26 (26\%), $0_{145}$ (12\%), $\mathrm{O}_{111}(10 \%)$ and $\mathrm{O}_{103}$ (5\%) [6].

\section{The outbreak}

Between 4 June and 9 August 2013, seven paediatric cases of HUS resident in the Apulia region (19,345 km2, ca 4 million inhabitants) or with a history of recent travel to the area were reported to the National Registry of HUS. This represented an excess with respect to the three to five cases per year annually reported in the Apulia region since 1988 [4], and laboratory investigation showed evidence of infection with STEC $0_{2} 6$ for four of the five cases whose clinical samples were examined. An outbreak limited to the Apulia region was suspected and an alert was issued to the regional health authorities. Investigations were started to find additional cases, identify the sources of infection, and limit the spread of the outbreak. This report describes the epidemiological, clinical, and microbiological features of the outbreak. 
Geographical distribution of recorded cases of haemolytic uraemic syndrome, Apulia region, Italy, 1 June to 30 September $2013(n=22)$

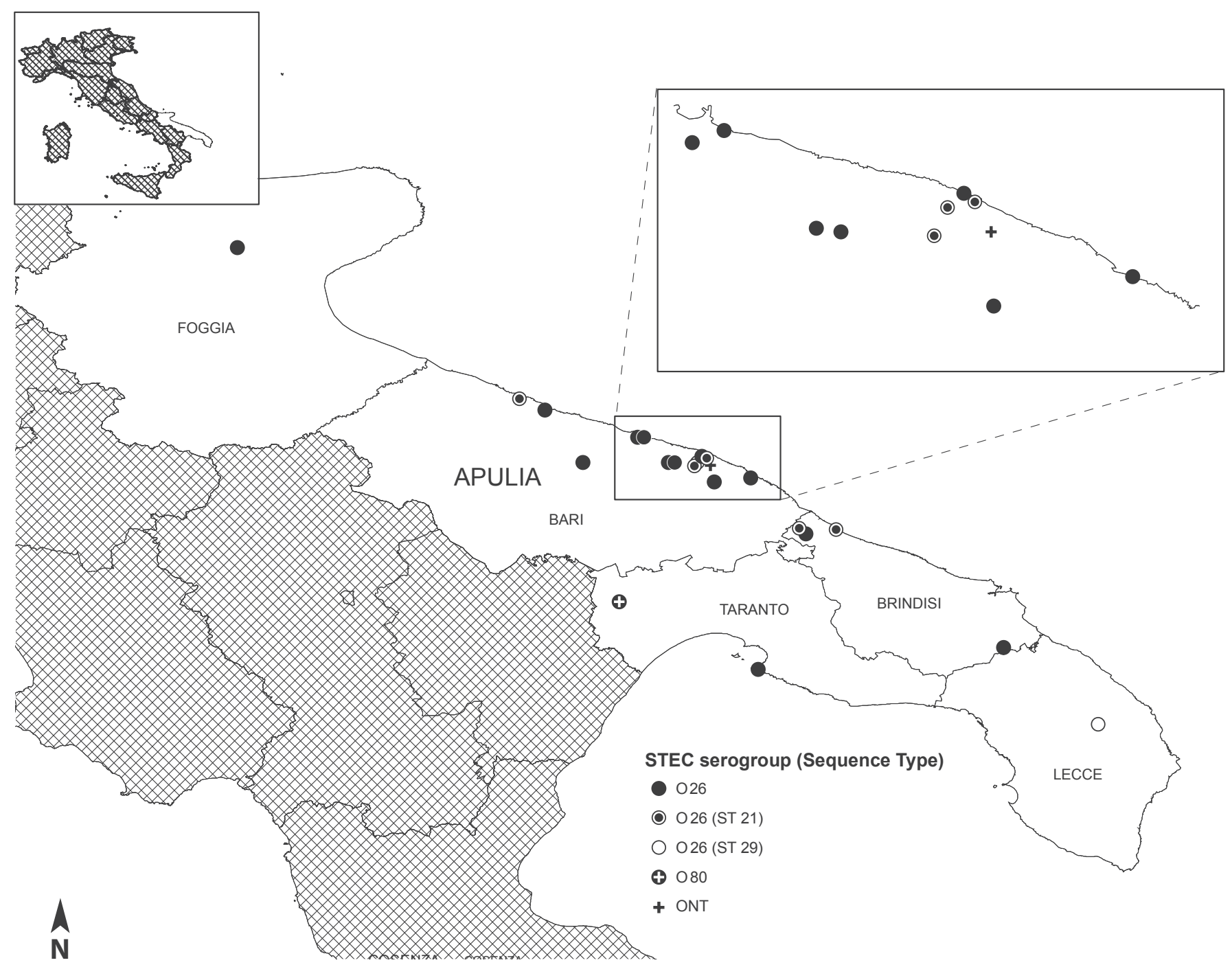

ONT: 0 non-typeable; STEC: Shiga toxin-producing Escherichia coli.

\section{Methods}

Case definition and case finding

A probable case was defined as a patient presenting with HUS, or with suspected HUS, or with bloody diarrhoea between 1 June and 30 September 2013, resident in, or with a history of travelling to the Apulia region during the 15 days before the onset of illness. A confirmed case was defined as a patient with diarrhoea or HUS, and laboratory evidence of infection with STEC O26. HUS cases were defined according to Tozzi et al. [4] as patients with evidence of renal failure, intravascular haemolysis, and thrombocytopenia (platelet count $<100,000 / \mathrm{mm} 3)$.

In the Apulia region, the active case finding was carried out by alerting hospitals and emergency rooms to promptly report to the regional surveillance system for infectious diseases any case of bloody diarrhoea, or HUS, or suspected HUS and to submit stool and serum samples for the laboratory diagnosis of STEC infection. The case-finding was extended at the national and international level by posting alerts through the dedicated information systems coordinated by the National HUS Registry and the European Centre for Disease Prevention and Control (ECDC).

\section{Laboratory diagnosis of Shiga toxin} 2-producing Escherichia coli infection

Stool samples were inoculated in buffered peptone water (BPW) and incubated at $37^{\circ} \mathrm{C}$ for 18 hours. DNA was extracted from $1 \mathrm{~mL}$ of the culture with the InstaGene Matrix (Bio-rad Laboratories, Hercules, CA, US) and tested by a real-time PCR assay to detect the presence of Stx- (stx1 and stx2) [7] and intimin (eae)coding genes [8]. PCR-positive samples were streaked 
Distribution of cases of haemolytic uraemic syndrome by infection with different Shiga toxin-producing Escherichia coli strains, Apulia region, Italy, 1 June to 30 September $2013(n=22)$

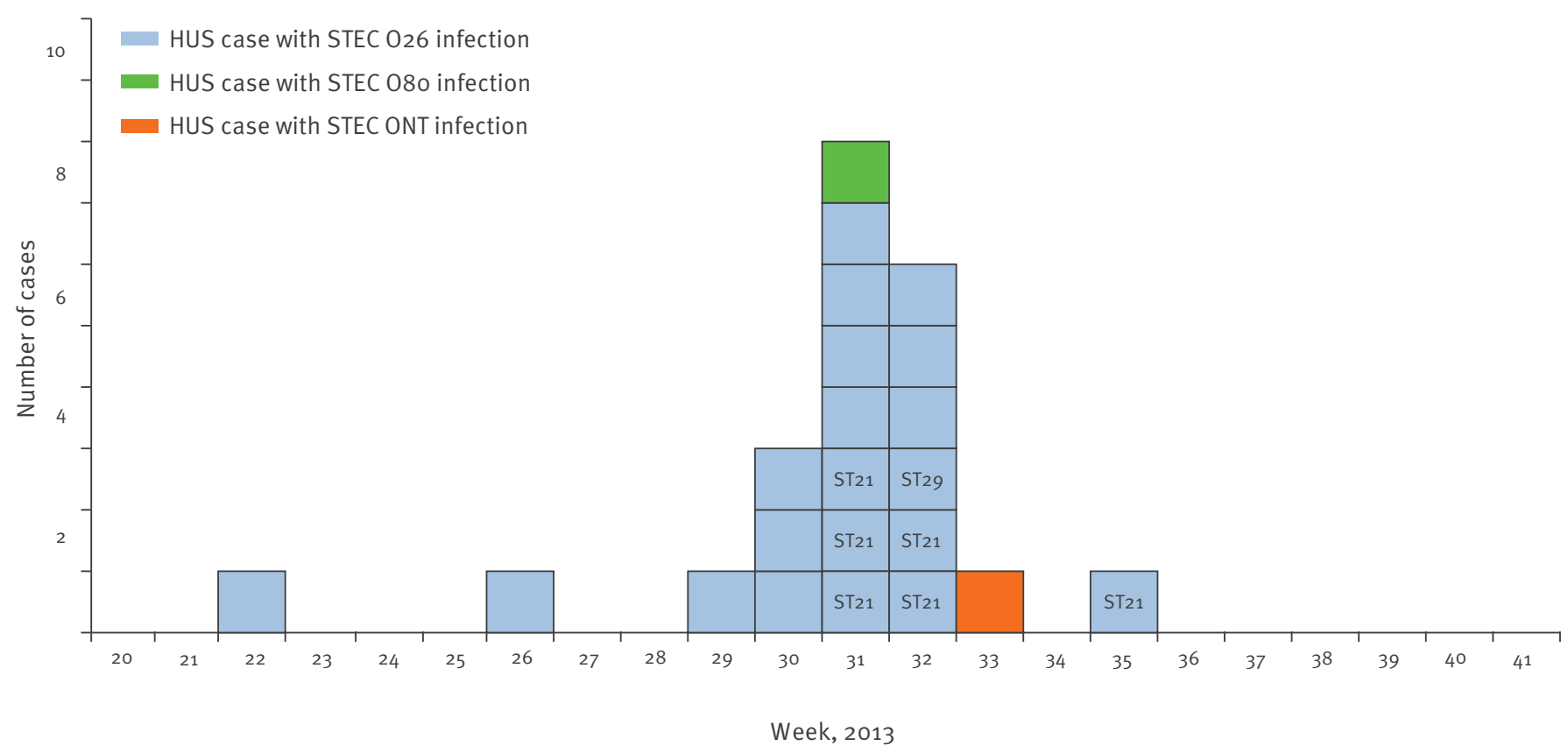

HUS: haemolytic uraemic syndrome; ONT: O non-typeable; STEC: Shiga toxin 2-producing Escherichia coli.

Boxes represent HUS cases and are coloured according to the different STEC O serogroups. Where available, the sequence type (ST) of the infecting STEC 026 strain is indicated in the box.

onto MacConkey agar plates and colonies resembling E. coli tested for the presence of stx and eae genes by PCR [9]. The stx and/or eae-positive strains were tested with $O$ antisera against the main STEC serogroups (Statens Serum Institut, Copenhagen, Denmark) by slide agglutination. Serotyping of STEC belonging to other serogroups was kindly performed by F. Scheutz, at the Statens Serum Institut, Copenhagen, Denmark. Stools were also examined for the presence of free Stx by the Vero cell cytotoxicity assay [4]. Serum samples were tested for antibodies to the lipopolysaccharide (LPS) of five major STEC serogroups (0157, O26, $\mathrm{O}_{103}$, O111, and 0145) by ELISA [10].

\section{Characterisation of the Shiga toxin}

\section{2-producing Escherichia coli 026 strains}

The flagellar (H-antigen) flic alleles were detected by real-time PCR, as described by Madic et al. [11]. The stx gene subtyping was carried out by PCR, as described by Scheutz et al. [12]. PFGE (Pulsed-Field Gel Electrophoresis) was performed as previously described [9]. Similarity of PFGE profiles was evaluated using the Bionumerics software (Applied Maths, SintMartens-Latem, Belgium), using the UPGMA algorithm with tolerance and optimisation set at $1.5 \%$.

Multilocus sequence typing (MLST) was performed using the scheme developed by Wirth et al. [13].
Sequence types (STs) were determined using the tool available at the University of Warwick [13].

\section{Epidemiological investigation}

Parents of confirmed cases were interviewed using the HUS Registry questionnaire, after giving their informed consent. Age, sex, type and time of onset of clinical symptoms, and food and environmental exposures for STEC infection in the 7 days before illness onset were annotated. Other information included dietary habits, food and water consumption, exposure to livestock, presence of household contacts with diarrhoea, exposures to potential environmental sources of STEC, and travel in the 2 weeks before the onset of symptoms.

\section{Food trace-back investigation}

Trace-back investigations were mainly focused on the retail outlets that sold dairy products and vegetables to the families of the cases in the two weeks before the onset of symptoms. Based on the interviews, it was hypothesised that these products might be implicated in the transmission of STEC infection to patients. Indeed, they were the only items consumed by most of the cases, for which the mode of preparation and consumption would not have eliminated any possible contamination with STEC.

The identified dairy plants were inspected and their staff interviewed by local health authorities regarding 
Dendrogram of the degree (\%) of similarity between pulsed-field gel electrophoresis profiles of XbaI-digested genomic DNA from strains of Escherichia coli $\mathrm{O} 26$ isolated from cases of haemolytic uraemic syndrome and dairy products, Apulia region, Italy, 1 June and 30 September 2013

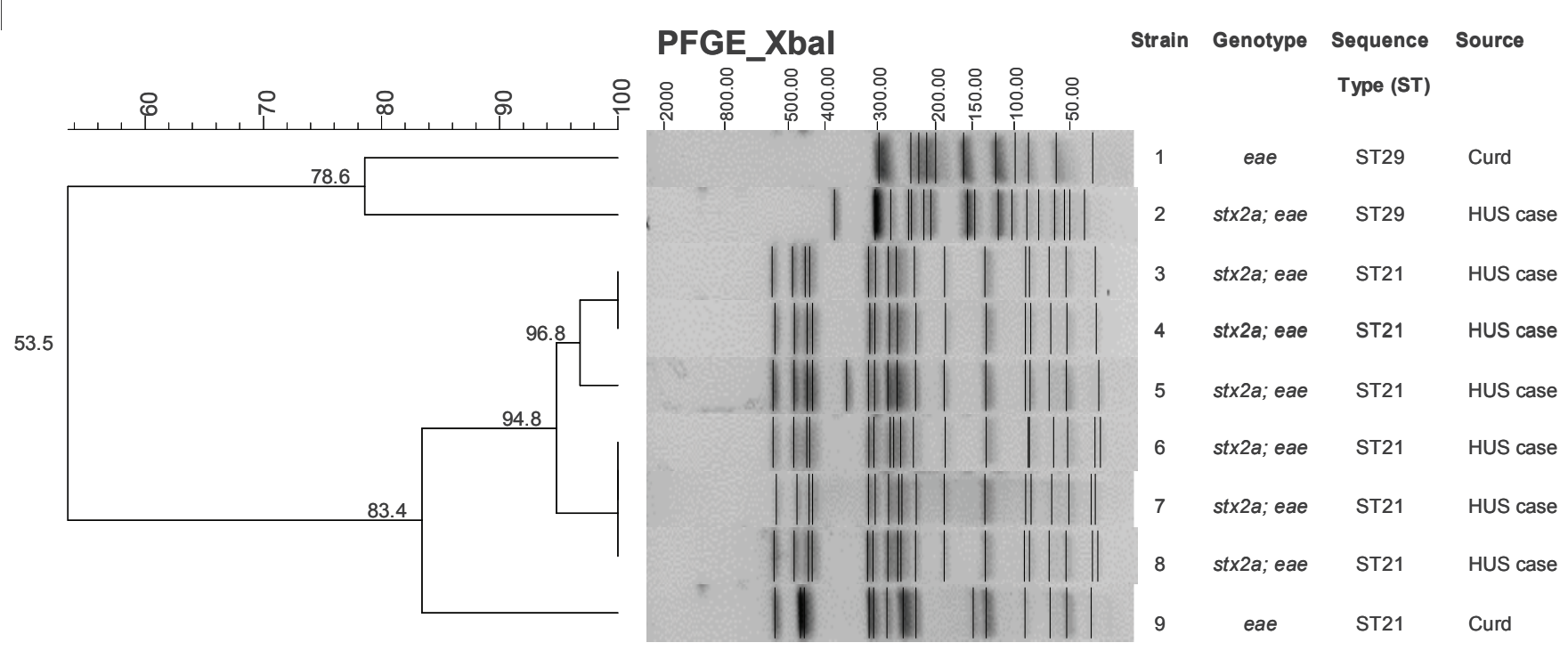

processing practices and sources of raw materials. The dairy farms that supplied milk to the plants were identified and visited as well. Samples of ready-to-eat dairy products, curd, raw milk, fruit and vegetables, and ground beef were collected and tested for the presence of STEC 026 according to the ISO/TS 13136:2012 method for the detection of STEC in food. Briefly, $25 \mathrm{~g}$ of each sample were enriched in BPW at $37^{\circ} \mathrm{C}$ for $18 \mathrm{~h}$. DNA was extracted from one $\mathrm{mL}$ of the enrichment culture with the InstaGene Matrix and tested by realtime PCR for the presence of $s t \times 1$, stx2, and eae genes. Positive DNA samples were further tested for the wzx gene associated to the 026 E. coli antigen [7]. Positive enrichment cultures were subjected to an 026-specific immunomagnetic separation followed by plating on MacConkey Agar. Colonies were tested for the presence of stx and/or eae genes by PCR amplification [9].

\section{Environmental investigation}

Marine water samples were collected from seaside locations that had been attended by some of the cases. Water samples $(250 \mathrm{~mL})$ were subjected to filtration through membranes of mean pore size $0.45 \mu \mathrm{m}$. Membranes were then transferred to BPW for enrichment at $37^{\circ} \mathrm{C}$ for $18 \mathrm{~h}$. DNA extraction and real-time PCR assays for STEC virulence genes were carried out as described for stool and food samples.

\section{Case-control study}

A case-control study, limited to the 15 laboratory confirmed cases resident in the Apulia region, was conducted to identify exposures associated with STEC 026 infection in the 10 days before illness onset. Controls, up to five for each case, were children who were reported not to have had diarrhoea in the month preceding the interview, randomly selected among the patients of the family paediatricians of the cases. Controls were matched by sex, age and area of residence. Exposures possibly associated with STEC infection and reported by cases during the hypothesis generation were investigated. Cases and controls were interviewed face-to-face and by telephone, respectively. Exposures associated with STEC 026 infection were analysed by exact univariate and multivariate logistic regression. For subjects reporting consumption of dairy products, univariate and multivariate analyses were carried out to identify associations between STEC 026 infection and the dairy plant of origin of the artisan products of bovine origin. The level of significance was set at $p<0.05$. Data were analysed by Stata 11 MP (StataCorp LP, College Station, Texas).

\section{Results}

Case finding and diagnosis of Shiga toxin 2-producing Escherichia coli infection Between 1 June and 30 September 2013, 17 children with HUS resident in the Apulia region were admitted to the regional paediatric nephrology centre participating in the National HUS Registry. Two of the 17 cases were siblings and fell ill 10 days apart. The active casefinding revealed five additional children with HUS with a history of travel to the Apulia region: four were diagnosed in other Italian hospitals and one in a Swiss hospital. Figure 1 shows a map of the Apulia region with the location of the HUS cases at the onset of prodromal symptoms.

Stool and serum samples were obtained from 19 HUS cases, and serum only from the remaining three. The mean interval between onset of enteric symptoms and stool collection was 9 days (range 5-14 days). Stool 


\section{TABLE 1}

Evidence of Shiga toxin-producing Escherichia coli infection in 22 cases admitted to hospital with haemolytic uraemic syndrome between 1 June and 30 September 2013 and resident in or with a history of travel to Apulia region, Italy in the 15 days before illness onset

\begin{tabular}{|l|c|}
\hline Laboratory diagnosis: Type of evidence & No. of cases \\
\hline Infection with STEC 026 (confirmed cases): & 20 \\
\hline $\begin{array}{l}\text { Isolation of E. coli 026:H11 (stx2a+, eae }+ \text { ) and } \\
\text { O26 LPS antibodies }\end{array}$ & 7 \\
\hline $\begin{array}{l}\text { Free faecal Stx and/or stx2 genes, and 026 LPS } \\
\text { antbodies: 4 cases }\end{array}$ & 4 \\
\hline O26 LPS antibodies only & 9 \\
\hline Infection with other STEC: & 2 \\
\hline Isolation of E. coli 080:H2 (stx2f+,eae+) & 1 \\
\hline Isolation of E. coli ONT (stx2 group +,eae+) & 1 \\
\hline
\end{tabular}

LPS: lipopolysaccharide; ONT: O non-typeable; STEC: Shiga toxin 2-producing Escherichia coli; Stx: Shiga toxin.

examination yielded the isolation of STEC $\mathrm{O}_{2} 6: \mathrm{H}_{11}$ strains positive for the stx2a and eae genes from seven cases. STEC strains belonging to serotypes $080: \mathrm{H}_{2}$, positive for stx2f and eae, and 0 non-typeable (NT) positive for stx2 group and eae were isolated from two other cases. Four other cases had the enrichment cultures positive for stx 2 genes in PCR and/or had free faecal Stx. Serum antibodies against the LPS of E. coli 026 were detected in 20 cases. The two patients with STEC belonging to other serogroups did not have antibodies to any of the LPS tested (Table 1). For the six cases with serum antibodies against the LPS of E.coli 026 and STEC and Stx-negative faeces, the mean interval between onset of symptoms and stool collection was 10.5 days, longer than that of cases with Stx-positive stools (7 days). Overall, the evidence of infection with STEC 026 was obtained for 20 cases: 16 were resident in the Apulia region and four were travel-related. STEC 026 was isolated from five residents and two travelrelated cases.

The active case finding also allowed the identification of 20 cases of bloody diarrhoea whose stools were negative for salmonella and campylobacter and were examined for the presence of STEC. A STEC 0157 strain was isolated from one of these patients while the faeces of the other 19 were negative for stx and eae genes. Stool samples were also obtained from 26 of 40 household contacts of 12 confirmed cases. No STEC strains were isolated, but one sample collected by an adult and one from a child, both presenting with gastroenteric symptoms, tested positive in PCR for the stx 2 and the eae gene, respectively.

In the 20 confirmed cases with STEC 026 infection, the onset of symptoms occurred between 4 June and 8 September 2013 (Figure 2).

\section{Case characteristics}

The age of the 20 confirmed cases ranged from 11 to 78 months (mean: 24 months; median: 17 months). Eleven cases were female. All confirmed cases developed HUS. Prodromal diarrhoea was reported for 18 cases, and in 10 of them it was bloody. The median interval between onset of diarrhoea and diagnosis of HUS was 9 days (range 1-20 days). Vomiting, abdominal pain, and fever $\left(>38^{\circ} \mathrm{C}\right)$ were reported for 16,9 , and 6 cases, respectively. Other clinical details were available for 19 children. On admission, six cases presented neurological symptoms, primarily seizures $(n=5)$. Seven cases had haematuria and 10 cases had oliguria or anuria. Four cases underwent haemodialysis and plasma exchange, and four patients haemodialysis only. Blood transfusions were administered to 17 patients and 13 also received plasma infusion. Severe neurological sequelae as of 18 months after the onset of HUS were reported for two cases. One of these children also presented a light chronic renal failure.

\section{Source hypothesis generation}

Parents of children were interviewed to generate hypotheses about sources of infection but no obvious link was identified that could explain a significant number of them. Of the 19 confirmed cases that could be interviewed, four had household members with diarrhoea in the 15 days before the onset of illness and six reported contact with farm animals. As for food exposure, of the 18 patients for which the information was available, most cases reported consumption of cooked bovine meat (78\%), pasteurised or UHT milk $(61 \%)$, yoghurt $(72 \%)$, artisanal dairy products (mainly ricotta and mozzarella cheese) of bovine origin (100\%), fresh fruit (61\%) and watermelon (83\%), with multiple brands and/or food retailers involved. Interviews also revealed that two seaside beaches were attended by two and four cases, respectively.

\section{Trace-back investigations and laboratory examination of food and environmental samples}

The dairy products of bovine origin consumed by 16 confirmed cases had been prepared by at least six different plants (Table 2). These plants were inspected between 20 August 2013 and 13 September 2013, as well as other 14 dairy plants supplying the retail outlets attended by the cases' families. Recommendations for implementing hygiene measures and good manufacturing practices were issued. The activity of one plant showed gross hygiene failures and was suspended. Pasteurisation of milk for dairy product production was prescribed to three other plants. Visits were also carried out to 31 dairy farms that supplied raw milk to the plants. A total of 218 samples of raw milk and dairy products of bovine origin were collected and tested for the presence of STEC. Sixty-five samples of fruit and vegetables, in particular watermelon, and five beef samples were also collected at retail and wholesale outlets identified through the trace-back investigations and tested for STEC. All the fruit, vegetable, and beef 
Presence of Escherichia coli $\mathrm{O} 26$ and/or its virulence genes in bulk milk or curd samples collected in the Apulia region, Italy, 20 August to 13 September 2013

\begin{tabular}{|c|c|c|c|c|c|c|}
\hline \multirow{3}{*}{ Dairy plant ${ }^{\mathrm{a}}$} & \multirow{3}{*}{$\begin{array}{l}\text { Confirmed cases associated } \\
\text { with the dairy plant } \\
n\end{array}$} & \multicolumn{5}{|c|}{ Number and type of samples associated with the dairy plants } \\
\hline & & \multicolumn{2}{|c|}{$\begin{array}{l}\text { Samples positive for stx, eae and } \\
\qquad \begin{array}{l}W Z x_{\mathrm{O}_{26}} \text { genes }\end{array}\end{array}$} & \multicolumn{3}{|c|}{ Samples with $E$. coli $\mathrm{O} 26$ isolation } \\
\hline & & $\mathrm{n}$ & Type of matrix & $\mathrm{n}$ & Type of matrix & Characteristics of the strain \\
\hline A & 3 & 3 & 1 curd, 2 bulk milk ${ }^{b}$ & 1 & curd & E. coli 026 stx-, eae+ \\
\hline B & 2 & 1 & bulk milk & 0 & 0 & 0 \\
\hline $\mathrm{C}$ & 7 & 0 & 0 & 0 & 0 & 0 \\
\hline $\mathrm{D}$ & 2 & 0 & 0 & 0 & 0 & 0 \\
\hline$E$ & 1 & 6 & 4 curd, 2 bulk milk & 2 & milk, curd & E. coli 026 stx-, eae+ \\
\hline $\mathrm{F}$ & 1 & 1 & bulk milk & 1 & milk & E. coli 026 stx-, eae+ \\
\hline $\begin{array}{l}\text { Other dairy } \\
\text { farms }\end{array}$ & Not possible to determine & 2 & bulk milk ${ }^{c}$ & 0 & 0 & 0 \\
\hline Total & 16 & 12 & 5 curd, 7 bulk milk & 4 & $\begin{array}{l}2 \text { milk, } \\
2 \text { curd }\end{array}$ & E. coli 026 stx-, eae+ \\
\hline
\end{tabular}

E. coli: Escherichia coli.

a Samples were collected directly at the plant or at dairy farms supplying milk to the plant.

b One bulk milk sample was from a farm that supplied both plant A and B.

'Two samples were positive for stx genes only.

Samples were from dairy plants linked with confirmed cases of Shiga toxin-producing Escherichia coli 026 infection or dairy farms supplying milk to the plants.

samples were negative. The enrichment cultures of 12 bulk milk or curd samples were positive for stx genes and, in 10 samples, for the eae and $\mathrm{wzXO}_{2} 6$ genes. $E$. coli $026: \mathrm{H}_{11}$ strains lacking the stx genes but positive for the eae gene were isolated from two curd and two bulk milk specimens (Table 2).

Fifteen marine water samples collected at the two seaside beaches attended by the cases proved negative for the presence of stx and eae genes.

\section{Characterisation of the Escherichia coli $\mathrm{O} 26$ strains}

The Stx-positive and Stx-negative E. coli 026 strains isolated respectively from cases and from dairy products were characterised by MLST and PFGE. All the strains belonged to the clonal complex ST29, but two different STs were distinguished: six strains from cases and one strain from food belonged to ST21, while one human and three food strains were ST29. PFGE analysis (Figure 3) of the strains isolated from cases showed similar profiles (between $94.8 \%$ and $100 \%$ similarity) for the six ST21 strains and a clearly different profile for the ST29 strain. The PFGE profiles of the two Stxnegative strains isolated from curd were not related with the two profiles of the human strains, and the two strains from milk were untypable due to degradation of DNA during the procedure.

\section{Case-control study}

Fifteen confirmed cases and 52 matched controls were included in the case-control study. No differences in the mean age $(t=0.2 ; p=0.80)$ and in the distribution by $\operatorname{sex}($ Chi-squared $=0.01 ; p=0.91$ ) were observed between cases and controls. In the univariate analysis (Table 3), STEC 026 infection was significantly associated with the consumption of products from dairy plants $A$ and $C$ but was associated neither with any individual dairy product from these plants nor with any other food items. Multivariate analysis confirmed the association for both plant $A$ (odds ratio (OR): 42.7; 95\% confidence interval $(\mathrm{Cl}): 2.4-750.5 ; \mathrm{p}=0.01)$ and plant $\mathrm{C}$ (OR:21.3; 95\% Cl:3.0-152.5; $\mathrm{p}<0.01$ ).

\section{Discussion}

This report describes the largest outbreak of STECassociated HUS ever observed in Italy. The STEC serotype involved was $026: \mathrm{H}_{11}$, which represents the most common cause of STEC non- $0_{157}$ infections in Europe $[2,14]$ and has been frequently associated with HUS worldwide $[3,4,15-18]$. In Italy, the proportion of HUS cases associated with STEC 026 infection has increased since the late 1990s, and currently exceeds that of STEC O157 [2].

This particular STEC serogroup seems to be evolving [5], with a shift from the stx1 to the stx 2 genotype in the strains associated with severe illness that occurred over the last two decades $[2,5,19]$. Such a phenomenon has public health relevance, since Stx2-producing $E$. coli 026 strains can cause a disease that is as severe as that caused by STEC 0157 [15,19-22]. Two of the cases involved in this episode reported severe neurological sequelae.

At the time of writing this report, to our knowledge, the episode herein described represented the second community-wide outbreak of HUS caused by Stx2-producing 
E. coli $\mathrm{O} 26$ after that involving 16 HUS cases in France in 2005 , linked to the consumption of unpasteurised cow's cheese (camembert) [16,23]. Another severe community-wide outbreak of HUS mainly associated with STEC 026 infection was been reported in Romania in early 2016, with at least 15 children involved [24].

In the Italian outbreak, as in other STEC communitywide outbreaks $[10,25-28]$, cases occurred over a large geographic area and a prolonged period of time and were observed in the framework of a HUS surveillance system, confirming that the emergence of HUS clusters represents an important sentinel event for outbreak recognition $[2,10,25,26]$. In this episode, an active case finding was promptly implemented after the alert to find new cases, improving the sensitivity and the promptness of case reporting. The enhanced regional surveillance system facilitated the outbreak investigation as well as the adoption of public health measures. Moreover, the existence of national HUS surveillance systems allowed a timely finding of STEC 026 cases resident in other Italian regions and in Switzerland, and who had visited Apulia.

A prompt and accurate laboratory diagnosis of STEC infection is of the utmost importance in HUS cases, to assess the STEC serotype/genotype involved. In 13 out of the 20 cases involved in this episode, the diagnosis of STEC 026 infection was based only on the detection of LPS antibodies, confirming the importance of LPS serology in identifying STEC 0157 and non-0157 infections in HUS patients $[4,10,16]$. Molecular typing of the seven STEC 026: $\mathrm{H}_{11}$ isolates from cases showed that two distinct STEC 026 strains were involved in the outbreak, with the one belonging to ST21 playing a major role. The concomitant presence of two different STEC 026:H11 strains and the two cases of HUS due to different STEC serotypes in the same area and period of time suggest the possibility of a multiple-aetiology outbreak [29]. Outbreaks with different non-0157 STEC strains, including STEC 026, have been reported in the United States [29], Belgium [30] and France [16,23]. As in our case, one of them involved two STEC strains belonging to serotypes $026: \mathrm{H}_{11}$ and $080: \mathrm{H}_{2}[16,23]$ and another one, two STEC 026 strains displaying different PFGE profiles [29].

Multiple-aetiology outbreaks have been frequently associated with exposures to environmental sources [29]. Some of the cases shared exposure to the same seaside locations, but water samples collected at those places proved negative for STEC, although the size of the samples may have been too small to allow the detection of the pathogen. However, in this outbreak the spread of cases in a large geographic area makes environmental sources unlike.

Although the origin of human infections with Stx2producing $E$. coli 026 strains has rarely been identified [31], at least two episodes involving cases of HUS and associated with consumption of unpasteurised milk or dairy products have been reported in Austria [32] and France $[16,23]$. In our investigation, STEC 026 infection was significantly associated with the consumption of dairy products from two local plants and a drop in the occurrence of cases was observed after the adoption of control measures involving those plants. Neither the association of STEC $\mathrm{O}_{2} 6$ infection with specific products nor a laboratory evidence of STEC contamination in the final ready-to-eat dairy products could be demonstrated. However, we cannot exclude that a contaminated raw material with a prolonged shelf life, such as a frozen ingredient, could have been continuously used in local plants to prepare different fresh, readyto-eat products, even though no evidence of such use emerged from the visits to the dairy plants.

The possible involvement of dairy products was also suggested by the evidence of STEC contamination in some bulk milk and curd samples from different plants and by the isolation of stx-negative E. coli $\mathrm{O}_{2} 6: \mathrm{H}_{11}$ strains from four of these samples. The loss and transfer of stx genes by $E$. coli $\mathrm{O} 26$ has been demonstrated during human infections [33], and Stx2-positive and negative variants of the same STEC 026:H11 strain, as defined by PFGE analysis, have been isolated from both HUS cases and cheese samples in the French camembert-associated outbreak [23]. Conversely, in the present episode the PFGE profiles of the stx-negative $E$. coli $026: \mathrm{H}_{11}$ strains from milk and curd did not match those of the outbreak isolates.

Another interesting feature of this outbreak is that, despite the enhanced surveillance, we were unable to identify cases of STEC 026 infection other than young children with HUS. In outbreaks due to STEC 0157, conversely, severe diarrhoea is generally observed in all the age bands, with young children being more prone to develop HUS $[1,25]$. The apparent absence of adult cases of infection could be explained by a lack of exposure to the source of infection, even though the epidemiological investigation did not show any suspect food dedicated to small children or other possible STEC risk factors restricted to the young. Another possibility is that the outbreak source was contaminated at a very low level, albeit sufficient to cause disease in young children, the most susceptible age group. Stx2producing $E$. coli $\mathrm{O}_{2} 6$ is considered a highly virulent STEC [5]. Nonetheless, an analysis of the literature confirms that the reported outbreaks $[16,32]$ and severe cases $[15,19-22]$ have generally involved only young children. Moreover, in HUS surveys [4], children with STEC 026 infection have been reported to be younger than those with STEC 0157 infection. Altogether, these observations allow us to speculate that Stx2-producing E. coli 026 might exert a particular virulence towards young children, which could be the reflection of a better fitness of these pathogens in a particular intestinal environment, eventually resulting in an increased colonisation of the gastrointestinal tract. 
TABLE 3

Results of the case-control analysis of exposures in an outbreak of Shiga toxin-producing Escherichia coli O26 infection, Apulia region, Italy, 2013

\begin{tabular}{|c|c|c|c|c|}
\hline Exposure & $\begin{array}{l}\text { Cases } \\
(n=15)\end{array}$ & $\begin{array}{l}\text { Controls } \\
(n=52)\end{array}$ & $\begin{array}{c}\text { Matched OR } \\
(95 \% \mathrm{Cl})\end{array}$ & $p$-value \\
\hline \multicolumn{5}{|l|}{ Meat } \\
\hline Chicken & 11 & 33 & $\begin{array}{c}1.6 \\
(0.4-7.7) \\
\end{array}$ & 0.5 \\
\hline Frankfurter sausages & 4 & 8 & $2(0.4-9.2)$ & 0.3 \\
\hline Hamburger & 4 & 21 & $\begin{array}{c}0.6 \\
(0.1-2.8) \\
\end{array}$ & 0.4 \\
\hline Meatballs & 4 & 19 & $\begin{array}{c}0.5 \\
(0.1-2.4)\end{array}$ & 0.4 \\
\hline Pork & 5 & 19 & $\begin{array}{c}0.9 \\
(0.2-3.3) \\
\end{array}$ & 0.8 \\
\hline Sausages & 5 & 26 & $0.5(0.1-1.9)$ & 0.3 \\
\hline Veal & 12 & 28 & $\begin{array}{c}3.1 \\
(0.7-19.2)\end{array}$ & 0.1 \\
\hline \multicolumn{5}{|l|}{ Fruit and vegetables } \\
\hline Fresh fruit & 8 & 32 & $\begin{array}{c}0.7 \\
(0.2-2.7) \\
\end{array}$ & 0.6 \\
\hline $\begin{array}{l}\text { Green leafy } \\
\text { vegetables }\end{array}$ & 3 & 4 & $\begin{array}{c}2.9 \\
(0.4-19.3)\end{array}$ & 0.2 \\
\hline Fruit juice & 8 & 30 & $\begin{array}{c}0.8 \\
(0.2-3.2) \\
\end{array}$ & 0.8 \\
\hline Watermelon & 12 & 39 & $\begin{array}{c}1.3 \\
(0.3-8.5)\end{array}$ & 0.7 \\
\hline Other vegetables & 7 & 22 & $\begin{array}{c}1.2 \\
(0.3-4.4) \\
\end{array}$ & 0.8 \\
\hline \multicolumn{5}{|l|}{ Dairy products } \\
\hline Pasteurised milk & 5 & 15 & $\begin{array}{c}1.2 \\
(0.3-4.8) \\
\end{array}$ & 0.7 \\
\hline UHT milk & 4 & 24 & $\begin{array}{c}0.4 \\
(0.1-1.6) \\
\end{array}$ & 0.2 \\
\hline Yogurt & 11 & 31 & $\begin{array}{c}1.9 \\
(0.5-9.0) \\
\end{array}$ & 0.3 \\
\hline Burrata cheese & 3 & 5 & $\begin{array}{c}2.4 \\
(0.3-13.9) \\
\end{array}$ & 0.3 \\
\hline Mozzarella cheese & 8 & 22 & $\begin{array}{c}1.6 \\
(0.5-5.9) \\
\end{array}$ & 0.5 \\
\hline Ricotta cheese & 8 & 32 & $\begin{array}{c}0.7 \\
(0.2-2.6)\end{array}$ & 0.5 \\
\hline Other fresh cheeses & 3 & 28 & $\begin{array}{c}0.2 \\
(0.0-0.9)\end{array}$ & 0.2 \\
\hline \multicolumn{5}{|l|}{ Any dairy product from } \\
\hline Plant A & 3 & 1 & $\begin{array}{c}10.3 \\
(1.5-930.2) \\
\end{array}$ & $<0.01$ \\
\hline Plant B & 2 & 5 & $\begin{array}{c}1.4 \\
(0.1-10.1) \\
\end{array}$ & 0.7 \\
\hline Plant C & 7 & 5 & $\begin{array}{c}13.9 \\
(2.2-43.4)\end{array}$ & $<0.01$ \\
\hline Plant E & 1 & 2 & $\begin{array}{c}1.8 \\
(0.0-36.3)\end{array}$ & 0.6 \\
\hline \multicolumn{5}{|l|}{ Other food } \\
\hline Ice cream & 10 & 41 & $\begin{array}{c}0.5 \\
(0.1-2.5) \\
\end{array}$ & 0.3 \\
\hline
\end{tabular}

$\mathrm{Cl}$ : confidence interval; OR: odds ratio; UHT: ultra-high temperature processing.

Results are from the univariate analysis.
In conclusion, the present outbreak supports the view that infections with Stx2-producing $E$. coli $\mathrm{O}_{2} 6$ in children have a high probability to progress to HUS and represent an emerging public health problem in Europe [5]. This further underlines the importance of maintaining national and local surveillance systems for HUS for an early detection and response to STEC 026 infections.

\section{Members of the Outbreak investigation team}

Other participants of the outbreak investigation team: Francesco Desiante, Giulia Calabrese, Carmen Martino, Maria Filomena Gallone, Anna Morea (Department of Biomedical Science and Human Oncology, Aldo Moro University of Bari, Italy), Rosangela Tozzoli, Stefano Morabito (Department of Veterinary Public Health and Food Safety, Istituto Superiore di Sanità, Rome, Italy), Antonio Parisi (Istituto Zooprofilattico Sperimentale della Puglia e Basilicata, Putignano, Italy), Tommaso Depalo, Vincenza Carbone, Annalisa Resta (Paediatric Nephrology and Dialysis Unit, Children's Hospital Giovanni XXIII, Bari, Italy), Pierfrancesco Pinto (Veterinary Public Health Office, Regione Puglia, Bari, Italy ), Massimo Ricci (Regional Agency for Prevention and Environment Protection, Brindisi, Italy), Alessandra Gianviti (Children's Hospital Bambino Gesù, Rome, Italy), Gianluigi Ardissino (IRCCS Ospedale Maggior Policlinico, Clinica De' Marchi, Milan, Italy ).

\section{Acknowledgements}

Authors acknowledge Professor Giacomo Simonetti (Universitätsspital, Universitätsklinik für Kinderheilkunde, Kindernephrologie, Bern, Switzerland) for kindly providing clinical information on the outbreak case patient resident in Switzerland and a serum sample for STEC infection diagnosis.

\section{Conflict of interest}

None declared.

\section{Authors' contributions}

Diagnosis and clinical management of cases: M Giordano, L Santangelo. Contribution to the epidemiological investigations: C Germinario, MS Gallone, S Tafuri, G Scavia; Laboratory diagnosis of STEC infection: M Chironna, A Caprioli, F Minelli, A Maugliani. Molecular typing: V Michelacci, M Chironna. Trace-back investigations and implementation of the control measures: 0 Mongelli. Laboratory investigations on food: C Montagna. Contribution to the writing of the paper: G Scavia, A Caprioli, C Germinario. The members of the outbreak investigation team contributed to the clinical, epidemiological, laboratory, and trace-back investigations.

\section{References}

1. Tarr PI, Gordon CA, Chandler WL. Shiga-toxin-producing Escherichia coli and haemolytic uraemic syndrome.Lancet. 2005;365(9464):1073-86.PMID: 15781103

2. Caprioli A, Scavia G, Morabito S. Public Health Microbiology of Shiga Toxin-Producing Escherichia coli. In Enterohemorragic Escherichia coli and Other Shiga Toxin-Producing E.coli. Washington, DC: ASM Press; 2014. p. 245-259.

3. Page AV, Liles WC. Enterohemorrhagic Escherichia coli Infections and the Hemolytic-Uremic Syndrome.Med Clin North 
Am. 2013;97(4):681-95, xi. DOI: 10.1016/j.mcna.2013.04.001 PMID: 23809720

4. Tozzi AE, Caprioli A, Minelli F, Gianviti A, De Petris L, Edefonti A, et al. , Hemolytic Uremic Syndrome Study Group. Shiga toxin-producing Escherichia coli infections associated with hemolytic uremic syndrome, Italy, 1988-2000.Emerg Infect Dis. 2003;9(1):106-8. DOI: 10.3201/eido901.020266 PMID: 12533290

5. Bielaszewska M, Mellmann A, Bletz S, Zhang W, Köck $\mathrm{R}$, Kossow A, et al. Enterohemorrhagic Escherichia coli 026: $\mathrm{H}_{11} / \mathrm{H}-:$ a new virulent clone emerges in Europe. Clin Infect Dis. 2013;56(10):1373-81. DOI: 10.1093/cid/cito55 PMID: 23378282

6. Scavia G, Edefonti A, Vidal E, Emma F, Percoraro C, Amore $A$, et al. A twenty-two year epidemiological surveillance of pediatric aemolytic uremic syndrome in Italy. Pediatr Nephrol. 2011;26:1624-5.

7. Perelle S, Dilasser F, Grout J, Fach P. Detection by 5'-nuclease PCR of Shiga-toxin producing Escherichia coli $0_{26} 6,0_{55}$, 091, $\mathrm{O}_{103}, \mathrm{O}_{111}, \mathrm{O}_{113}, \mathrm{O}_{145}$ and $\mathrm{O}_{157} \mathrm{:H} 7$, associated with the world's most frequent clinical cases. Mol Cell Probes. 2004;18(3):185-92. DOI: 10.1016/j.mcp.2003.12.004 PMID 15135453

8. Nielsen EM, Andersen MT. Detection and characterization of verocytotoxin-producing Escherichia coli by automated 5 , nuclease PCR assay.J Clin Microbiol. 2003;41(7):2884-93. DOI: 10.1128/JCM.41.7.2884-2893.2003 PMID: 12843017

9. Scavia G, Staffolani M, Fisichella S, Striano G, Colletta S, Ferri G, et al. Enteroaggregative Escherichia coli associated with a foodborne outbreak of gastroenteritis. J Med Microbiol. 2008;57(Pt 9):1141-6. DOI: 10.1099/jmm.0.2008/001362-0 PMID: 18719185

10. Caprioli A, Luzzi I, Rosmini F, Resti C, Edefonti A, Perfumo $\mathrm{F}$, et al. Community-wide outbreak of hemolytic-uremic syndrome associated with non-0157 verocytotoxin-producing Escherichia coli. J Infect Dis. 1994;169(1):208-11. DOI: 10.1093/ infdis/169.1.208 PMID: 8277184

11. Madic J, Peytavin de Garam C, Vingadassalon N, Oswald E, Fach P, Jamet E, et al. Simplex and multiplex real-time PCR assays for the detection of flagellar (H-antigen) $\mathrm{fliC}$ alleles and intimin (eae) variants associated with enterohaemorrhagic Escherichia coli (EHEC) serotypes O26: $\mathrm{H}_{11}, \mathrm{O}_{103}: \mathrm{H}_{2}, \mathrm{O}_{111} \mathrm{H} 8$, 0145:H28 and 0157:H7. J Appl Microbiol. 2010;109(5):1696705.PMID: 20618885

12. Scheutz F, Teel LD, Beutin L, Piérard D, Buvens G, Karch H, et al. Multicenter evaluation of a sequence-based protocol for subtyping Shiga toxins and standardizing Stx nomenclature. J Clin Microbiol. 2012;50(9):2951-63. DOI: 10.1128/JCM.00860-12 PMID: 22760050

13. Wirth T, Falush D, Lan R, Colles F, Mensa P, Wieler LH, et al. Sex and virulence in Escherichia coli: an evolutionary perspective. Mol Microbiol. 2006;60(5):1136-51. DOI: 10.1111/j.1365-2958.2006.05172.x PMID: 16689791

14. European Centre for Disease Prevention and Control (ECDC). Surveillance of seven priority food-and waterborne diseases in the EU/EEA. Stockholm: ECDC; 2015 . Available from: http:// ecdc.europa.eu/en/publications/publications/food-andwaterborne-diseases-surveillance-report-2015.pdf

15. Gerber A, Karch H, Allerberger F, Verweyen HM, Zimmerhackl LB. Clinical course and the role of shiga toxin-producing Escherichia coli infection in the hemolytic-uremic syndrome in pediatric patients, 1997-2000, in Germany and Austria: a prospective study.J Infect Dis. 2002;186(4):493-500. DOI: 10.1086/341940 PMID: 12195376

16. Espié E, Grimont F, Mariani-Kurkdjian P, Bouvet $P$, Haeghebaert $\mathrm{S}$, Filliol I, et al. Surveillance of hemolytic uremic syndrome in children less than 15 years of age, a system to monitor 0157 and non-0157 Shiga toxin-producing Escherichia coli infections in France, 1996-2006. Pediatr Infect Dis J. 2008;27(7):595-601. DOI: 10.1097/INF.obo13e31816a062f PMID: 18520972

17. Käppeli U, Hächler H, Giezendanner N, Beutin L, Stephan R. Human infections with non-0157 Shiga toxin-producing Escherichia coli, Switzerland, 2000-2009.Emerg Infect Dis. 2011;17(2):180-5. DOI: 10.3201/eid1702.100909 PMID: 21291586

18. Rivas M, Miliwebsky E, Chinen I, Roldán CD, Balbi L, García $B$, et al. , Case-Control Study Group. Characterization and epidemiologic subtyping of Shiga toxin-producing Escherichia coli strains isolated from hemolytic uremic syndrome and diarrhea cases in Argentina.Foodborne Pathog Dis. 2006;3(1):88-96. DOI: 10.1089/fpd.2006.3.88 PMID: 16602984

19. Ricotti GC, Buonomini MI, Merlitti A, Karch H, Luzzi I, Caprioli A. A fatal case of hemorrhagic colitis, thrombocytopenia, and renal failure associated with verocytotoxin-producing, non-0157 Escherichia coli.Clin Infect Dis. 1994;19(4):815-6. DOI: $10.1093 /$ clinids/19.4.815 PMID: 7803672
20. Pollock KG, Bhojani S, Beattie TJ, Allison L, Hanson M, Locking ME, et al. Highly virulent Escherichia coli 026 , Scotland. Emerg Infect Dis. 2011;17(9):1777-9. DOI: 10.3201/ eid1709.110199 PMID: 21888827

21. Zieg J, Dusek J, Marejkova M, Limrova P, Blazek D, Pavlicek $P$, et al. Fatal case of diarrhea-associated hemolytic uremic syndrome with severe neurologic involvement. Pediatr Int. 2012;54(1):166-7. DOI: 10.1111/j.1442-200X.2011.03533.x PMID: 22335333

22. Zimmerhackl LB, Rosales A, Hofer J, Riedl M, Jungraithmayr T, Mellmann A, et al. Enterohemorrhagic Escherichia coli 026:H11-Associated Hemolytic Uremic Syndrome: Bacteriology and Clinical Presentation. Semin Thromb Hemost. 2010;36(6):586-93. DOI: 10.1055/s-0030-1262880 PMID: 20865635

23. Institut de Veille Sanitaire (InVS). Epidémie d'infections à E.coli producteurs de Shiga toxins non-0157 liée à la consommation de camembert au lait cru, Nord-Ouest de la France, OctobreDécembre 2005. [Outbreak of Shiga toxin 2-producing Escherichia coli infections linked to consumption of raw-milk camembert, north-west France, October-December 2005]. France: Production scientifique InVS; 2007. [Accessed 21 Jun 2015]. French. Available from: http://opac.invs.sante.fr/index. php?lvl=notice_display\&id $=9416$

24. Peron E, Zaharia A, Zota L C, Severi E, Mardh O, Usein C, et al. Early findings in outbreak of haemolytic uraemic syndrome among young children caused by Shiga toxin-producing Escherichia coli, Romania, January to February 2016. Euro Surveill. 2016;21(11):30170

25. King LA, Mailles A, Mariani-Kurkdjian P, Vernozy-Rozand C, Montet MP, Grimont F, et al. Community-wide outbreak of Escherichia coli $\mathrm{O}_{157}: \mathrm{H}_{7}$ associated with consumption of frozen beef burgers. Epidemiol Infect. 2009;137(6):889-96. DOI: 10.1017/So950268808001490 PMID: 18945376

26. Ammon A, Petersen LR, Karch H. A large outbreak of hemolytic uremic syndrome caused by an unusual sorbitol-fermenting strain of Escherichia coli 0157:H-.J Infect Dis. 1999;179(5):12747. DOI: $10.1086 / 314715$ PMID: 10191236

27. Werber D, Fruth A, Liesegang A, Littmann M, Buchholz $\mathrm{U}$, Prager $\mathrm{R}$, et al. A multistate outbreak of Shiga toxinproducing Escherichia coli $026: \mathrm{H}_{11}$ infections in Germany, detected by molecular subtyping surveillance. J Infect Dis. 2002;186(3):419-22. DOI: 10.1086/341457 PMID: 12134240

28. Ethelberg S, Smith B, Torpdahl M, Lisby M, Boel J, Jensen T, et al. Outbreak of non-0157 Shiga toxin-producing Escherichia coli infection from consumption of beef sausage. Clin Infect Dis. 2009;48(8):e78-81. DOI: 10.1086/597502 PMID: 19272017

29. Luna-Gierke RE, Wymore K, Sadlowski J, Clogher P, Gierke RW, Tobin-D’Angelo M, et al. Multiple-aetiology enteric infections involving non-0157 Shiga toxin-producing Escherichia coli-FoodNet, 2001-2010. Zoonoses Public Health. 2014;61(7):4928. DOI: $10.1111 /$ zph.12098 PMID: 24484079

30. De Schrijver K, Buvens G, Possé B, Van den Branden D, Oosterlynck O, De Zutter L, et al. Outbreak of verocytotoxinproducing $\mathrm{E}$. coli $\mathrm{O}_{145}$ and $\mathrm{O}_{2} 6$ infections associated with the consumption of ice cream produced at a farm, Belgium, 2007. Euro Surveill. 2008;13(7):13.PMID: 18445416

31. Jenkins C, Evans J, Chart H, Willshaw GA, Frankel G. Escherichia coli serogroup 026--a new look at an old adversary.J Appl Microbiol. 2008;104(1):14-25.PMID: 18171379

32. Allerberger F, Friedrich AW, Grif K, Dierich MP, Dornbusch $\mathrm{HJ}$, Mache CJ, et al. Hemolytic-uremic syndrome associated with enterohemorrhagic Escherichia coli 026:H infection and consumption of unpasteurized cow's milk. Int J Infect Dis. 2003;7(1):42-5. DOI: 10.1016/S1201-9712(03)90041-5 PMID: 12718809

33. Bielaszewska M, Prager R, Köck R, Mellmann A, Zhang W, Tschäpe $H$, et al. Shiga toxin gene loss and transfer in vitro and in vivo during enterohemorrhagic Escherichia coli 026 infection in humans. Appl Environ Microbiol. 2007;73(10):314450. DOI: 10.1128/AEM.02937-06 PMID: 17400784

\section{License and copyright}

This is an open-access article distributed under the terms of the Creative Commons Attribution (CC BY 4.0) Licence. You may share and adapt the material, but must give appropriate credit to the source, provide a link to the licence, and indicate if changes were made.

This article is copyright of the authors, 2016. 